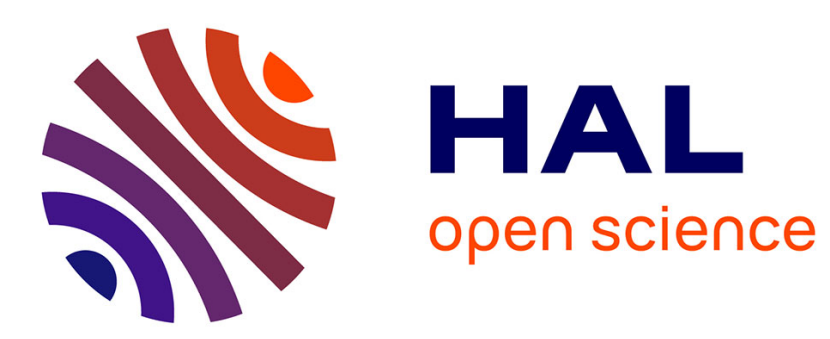

\title{
ELECTROMAGNETIC THEORY OF ENHANCED NONLINEAR OPTICAL PROCESS
}

\author{
M. Nevière, R. Reinisch
}

\section{To cite this version:}

M. Nevière, R. Reinisch. ELECTROMAGNETIC THEORY OF ENHANCED NONLINEAR

OPTICAL PROCESS. Journal de Physique Colloques, 1983, 44 (C10), pp.C10-349-C10-352. 10.1051/jphyscol:19831070 . jpa-00223528

\section{HAL Id: jpa-00223528 https://hal.science/jpa-00223528}

Submitted on 1 Jan 1983

HAL is a multi-disciplinary open access archive for the deposit and dissemination of scientific research documents, whether they are published or not. The documents may come from teaching and research institutions in France or abroad, or from public or private research centers.
L'archive ouverte pluridisciplinaire HAL, est destinée au dépôt et à la diffusion de documents scientifiques de niveau recherche, publiés ou non, émanant des établissements d'enseignement et de recherche français ou étrangers, des laboratoires publics ou privés. 


\title{
ELECTROMAGNETIC THEORY OF ENHANCED NONLINEAR OPTICAL PROCESS
}

\author{
M. Nevière and R. Reinisch*
}

Laboratoire d'optique Electromagnétique, E.R.A. 597 CNRS, Faculté des Sciences et Techniques, Centre de St-Jérôme, 13397 Marseizle Cedex 13, France

*aboratoire de Génie Physique, E.R.A. 836 CNRS, Domaine Universitaire, B.P. 46, 38402 Saint-Martin d'Hères, France

\begin{abstract}
Rêsumé - Nous développons une théorie électromagnétique rigoureuse de la diffraction de la lumière par un réseau rayé sur un matêriau non linéaire. Cette théorie permet $I^{\prime}$ étude de $1^{\prime}$ effet Raman géant ou de la génération de second harmonique renforcée par les rugosités de surface.

Abstract - We develop a rigorous electromagnetic theory of diffraction of light by a grating impressed on a nonlinear material. The theory can be used to study Surface. Enhanced Raman Scattering or Second Harmonic Generation.
\end{abstract}

\section{INTRODUCTION}

When two laser beams called "pump beams" with pulsatances $\omega_{1}$ and $\omega_{2}$ fall on a nonlinear material, they generate, through a nonlinear interaction, an electromagnetic field called "signal" at pulsatance $\omega_{3}=\omega_{1} \pm \omega_{2}$. A lot of experimental evidence shows that the intensity of the signal strongly depends on the surface roughness. If we assume the surface roughness to be periodic in order to take advantage of our experience in Grating Theory [1], [2], we see that the theory of enhanced nonlinear optical effects appears as a special case of the theory of diffraction by a grating in nonlinear optics. We present here a method which is the generalization to nonlinear optics of the theory described in [1]. It is valid for bare as well as dielectric coated gratings, whatever the groove shape may be (including phase gratings), takes into account all the diffraction phenomena at pulsatances $\omega_{1}, \omega_{2}$ and $\omega_{3}$, and is rigorously derived from Maxwel1 Equations. It works for any polarization of the pump beams and of the signal and can deal with metallic as we11 as dielectric materials.

\section{THE THEORY IN OUTLINE [3]}

We first divide space into three regions by means of planes $y=0$ and $y=\delta ; \delta$ is the thickness of the modulated region which is equal to the groove depth for the case illustrated on Fig. 1 .

Regions (1) and (3) are filled with homogeneous media, which are linear in (1) and nonlinear in (3). In the modulated region (2), both the permittivity $\varepsilon$ and the nonlinear polarization $\bar{S}^{\mathrm{NL}}$ are functions of $x$ and $y$ ( $\widehat{S}^{\mathrm{NL}}$ vanishes inside the grooves). No assumption is made concerning the

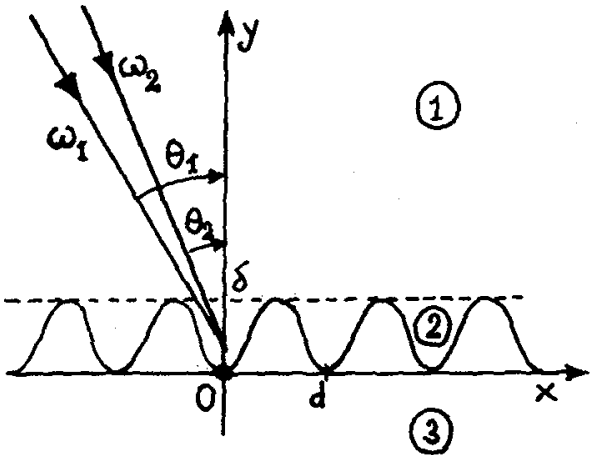

Figure 1 : Scattering geometry 
validity of Rayleigh expansions in the modulated region. The only approximation in the theory is the usual undepleted pump approximation for the two pump beams which is justified by the fact that the intensity of the signal is much smaller than those of the pump beams. It has the consequence that the two pump beams are linearly diffracted by the grating and that their diffraction phenomenon occurs independently of the nonlinear diffraction of the signal.

We thus develop an electromagnetic theory which consists of three steps :

i) In the first step, we study the diffraction of the two pump beams with the help of the rigorous linear electromagnetic theory of gratings [1] (Differential Formalism). We then get all the diffracted orders, radiated or evanescent, as well as the total electromagnetic field in the groove region, at pulsatances $\omega_{1}$ and $\omega_{2}$. ii) From the results of the first step, we calculate the nonlinear polarization $\widehat{J}^{N L}\left(\omega_{3}, x, y\right)$ inside and below the modulated region, whose expression depends on the nature (dielectric or metallic) of the grating material.

iii) In the third step, we integrate Maxwell equations in the modulated region at pulsatance $\omega_{3}$, the nonlinear polarization $\overrightarrow{\mathfrak{S}}^{\mathrm{NL}}\left(\omega_{3}, \mathrm{x}, \mathrm{y}\right)$ acting as the source of the $\omega_{3}$ electromagnetic field. We then get the electromagnetic field everywhere and, by comparison with a plane surface, we are able to determine enhancement factors due to surface roughness. By the time, we find the directions of the $\omega_{3}$ propagating orders through a simple formula which is the generalization of the classical grating equation and that we call the nonlinear grating equation [3].

\section{SECOND HARMONIC GENERATION IN SILVER $\left(\omega_{3}=\omega_{1}+\omega_{1}\right)$}

Among the various mechanisms leading to enhancement of second harmonic generation or Surface Enhanced Raman Scattering (chemical process, active sites, electromagnetic resonances ...), the scope of that theory is limited to the study of the third one. Concerning the electromagnetic resonances, the surface plasmon-polariton resonance is the first one which has been investigated to explain enhanced fields near gratings. But for dielectric coated gratings, a guided wave resonance can be found both in TE and TM polarizations and produces even higher enhancements. These resonances may appear at the pump frequency or at the signal frequency. Second harmonic generation is a phenomenon of special interest in that when a device is optimized to give the highest enhancement $F$ of the field intensity at pulsatance $\omega_{1}$, it is also optimized at pulsatance $\omega_{2}=\omega_{1}$. Thus, the source terms $\overrightarrow{\mathcal{O}}^{N L_{1}}\left(\omega_{3}, x, y\right)$ can be enhanced by a factor $\mathrm{E}=\mathrm{F}^{2}$, and a strong enhancement is expected for the $\omega_{3}$ field. The present theory shows that the field at pulsatance $\omega_{3}$ can even be enhanced by a factor $E^{\prime}$ much stronger than $E$. Let us first give results for the surface plasmon contribution.

\section{1) Surface plasmon resonance :}

Figure 2 shows the results for a silver sinusoidal grating. The wavelength $\lambda_{1}=2 \pi \mathrm{c} / \omega_{1}$ is $1.06 \mu \mathrm{m}$; the refractive index of silver, extrapolated from the values at $\lambda_{1} \leqslant 1$. $\mu \mathrm{m}$, has been taken equal to $0.163+i 7.2$. The groove spacing $d$, equal to $0.6174 \mu \mathrm{m}$, has been chosen in such a way to give a coupling through the +1 oxder under the incidence $45^{\circ}$. For a given groove depth $\delta$, the transmitted intensity $I_{1}$ of the +1 diffracted order is plotted as a function of $\theta_{1}$. When its wavevector longitudinal component $\frac{2 \pi}{\lambda_{1}} \sin \theta_{1}+\frac{2 \pi}{d}$

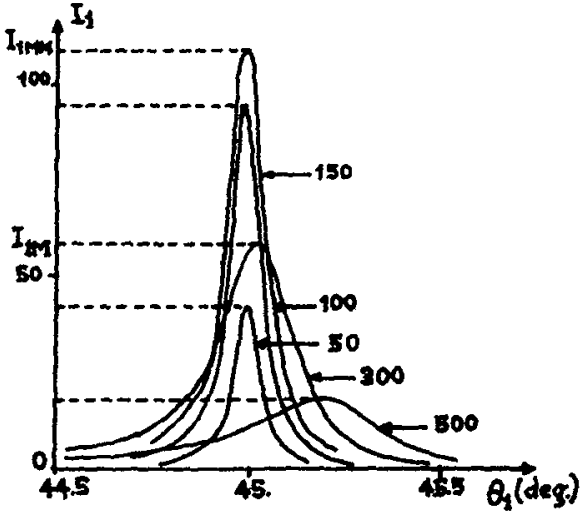

Figure 2 : Surface plasmon resonances at $\omega_{I}$ 
becomes close to the surface polariton wavevector longitudinal component $\beta_{S}\left(w_{l}\right)$, a strong maximum $\mathrm{I}_{1 M}$ occurs. Fig. 3 shows that $I_{1 M}$ itself strongly depends on the groove depth, and that the maximum maximorum found for $\delta=145 \mathrm{~A}^{\circ}$ is equal to 109.4 . If we let $\delta \rightarrow 0$ and calculate the intensity transmitted inside a silver plane (in the zero order), we find 3.817 , which leads to an enhancement factor $F=\frac{109.4}{3.817}=28.66$. The result is that the submicroscopic $145 \mathrm{~A}^{\circ}$ roughness can give an enhancement factor $E=F^{2}=821.4$ of the nonlinear polarization $\zeta^{N L}\left(\omega_{3}, x, y\right)$. From the values of the field at pulsatance $\omega_{1}$, we calculate inside the metal, the contribution to $\vec{f}^{\mathrm{NL}}\left(\omega_{3}, \mathrm{x}, \mathrm{y}\right)$ due to the volume term $\gamma \overrightarrow{\operatorname{grad}}\left[E^{2}\left(\omega_{1}, x, y\right)\right]$ (see eq. 2.1 of $[4]$ ); the contribution due to the surface term gives rise to nathematical problems in the theory and will be studied later. Then our computer program gives the intensity $\left|\mathrm{T}_{2}\right|^{2}$ of the resonant order at plusatance $\omega_{3}$ produced by that volume term. It reaches a maximum when $I_{l}$ of Fig. 2 was maximum. Calculating the intensity $\left|\mathrm{T}_{0}\right|^{2}$ of the field transmitted at pulsatance $\omega_{3}$ allows finding the enhancement factor E' of the signal intensity $\left(E^{\prime}=\frac{\mid T_{2}\left(\omega_{3}\right) \text { for the grating }\left.\right|^{2}}{\mid T_{0}\left(\omega_{3}\right) \text { for the plane }\left.\right|^{2}}\right.$ which reaches the value 40392 for $\theta=45^{\circ}$ (Fig. 3). That value is 49.2 times higher than the predicted enhancement $E$ of the sources. It shows that, due to the complicated structure of the transmitted field at pulsatance $\omega_{1}$ in presence of a modulated profile, the intensity of the resonance phenomenon at pulsatance $\omega_{3}$ cannot be accurately predicted from the strength of the field at pulsatance $w_{1}$.

Calculations for two different groove depths $\left(100\right.$ and $200 \mathrm{~A}^{\circ}$ ) show that $\delta=145^{\circ}$ which gives the optimal enhancement $F$ for the $\omega_{1}$ field also gives the optimal enhancement $\mathrm{E}^{\prime}$ for the $w_{3}$ field (Fig. 3).

2) Guided wave resonance :

In order to find a guided wave resonance, we now considex second harmonic generation in a silver grating coated by a dielectric layer with thickness $e=0.59 \mu \mathrm{m}$, and refractive index $v_{c}=1.49$. The groove frequency (1800 $\mathrm{mm}^{-1}$ ) is chosen in such a way that the +1 diffracted order is evanescent above the grooves and can be resonantly excited under

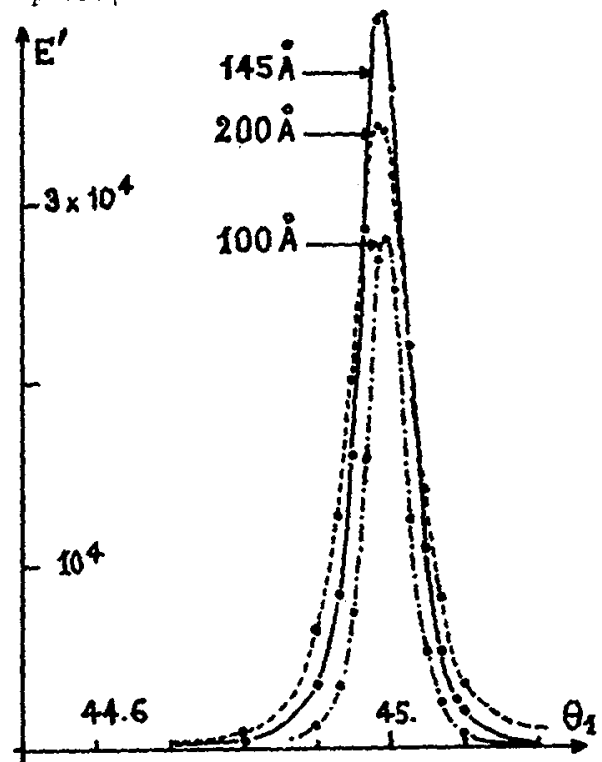

Figure 3 : Resonances at $\omega_{3}$ a convenient incidence $\theta=35.847^{\circ}$. The peak value I of the intensity of the field as a function of $\theta$ depends on $x, y$, and $\delta$. For each value of $\delta$, we have determined the coordinates of the point which leads to the greatest value $I_{M}$ of the peak value of this intensity. Doing the same work for several grooves depths, we were able to draw Fig. 4 which shows that it exists a convenient groove depth $\delta_{\text {opt }}\left(=150 \mathrm{~A}^{\circ}\right)$ which gives the highest value of $I_{M}$ called $I_{M M}$ (MM : maximum maximorum), equal to 543. If we compare the results with the field intensity inside a silver plane, we are led to the result that, this time, the nonlinear polarization $\mathcal{G}^{N L}\left(\omega_{3}, x, y\right)$ can be increased by a factor $\mathrm{E}=19385$. Another alternative is to compare to the case of second harnomic generation in the bulk dielectric with refractive index 1.49 and flat entrance face. We then get an enhancement factor $E=174467$. The conclusion is that the guided wave resonance can lead to much higher enhancements than the surface polariton resonance does. 


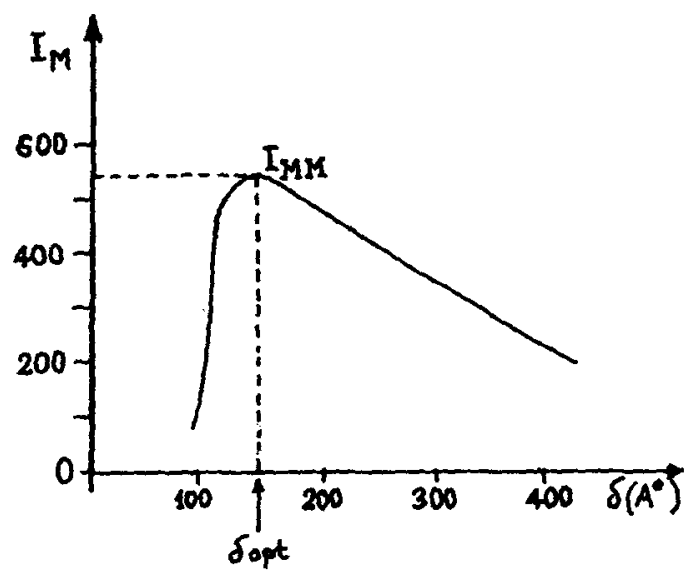

Tigure 4 : Evolution of the maximum intensity of the field in the groove region as a function of the groove depth. The incidence $\theta_{1}$ is $35.847^{\circ}$, $\lambda=1.06 \mu \mathrm{m}$ and the grating material is silver.

\section{CONCLUSION}

Many situations of interest for the Optician can be studied through the electromagnetic theory of diffraction by a grating in nonlinear optics we have developped, It not only allows determining the diffracted field, but also the field inside the material, whose resonance plays a key role in surface enhanced nonlinear effects. The nost striking result is that a submicroscopic roughness can increase the fields by several orders of magnitude and that the guided wave resonance can be even much more efficient than surface polariton resonance to increase nonlinear effects. Also, the enhancement of the signal intensity is much stronger than the square of the enhancement of the pump field.

\section{REFERENCES}

[1] Nevière, M., Vincent, P., and Petit, R., Nouv. Rev. Opt. 5 (1974), 65.

[2] Petit, R., Electromagnetic Theory of Gratings (Springer, Berlin), 1980 .

[3] Reinisch, R., and Nevière, M., Phys. Rev. B, to be published in the April issue.

[4] Agarwal, G.S., Jha, S.S., Phys. Rev. B, 26 (1982), 482. 